\title{
Design and Manufacturing Strategies for Fused Deposition Modelling in Additive Manufacturing: A Review
}

\author{
Hugo I. Medellin-Castillo ${ }^{*}$ and Jorge Zaragoza-Siqueiros
}

\begin{abstract}
Although several research works in the literature have focused on studying the capabilities of additive manufacturing (AM) systems, few works have addressed the development of Design for Additive Manufacturing (DfAM) knowledge, tools, rules, and methodologies, which has limited the penetration and impact of AM in industry. In this paper a comprehensive review of design and manufacturing strategies for Fused Deposition Modelling (FDM) is presented. Consequently, several DfAM strategies are proposed and analysed based on existing research works and the operation principles, materials, capabilities and limitations of the FDM process. These strategies have been divided into four main groups: geometry, quality, materials and sustainability. The implementation and practicality of the proposed DfAM is illustrated by three case studies. The new proposed DfAM strategies are intended to assist designers and manufacturers when making decisions to satisfy functional needs, while ensuring manufacturability in FDM systems. Moreover, many of these strategies can be applied or extended to other AM processes besides FDM.
\end{abstract}

Keywords: Additive manufacturing (AM), Design for additive manufacturing (DfAM), Fused Deposition Modelling (FDM), Design and manufacturing strategies

\section{Introduction}

The need to increase flexibility and speed up the design and manufacture process of new products led to the development of rapid technologies, including the additive manufacturing (AM) techniques (also known as rapid prototyping, rapid manufacturing, rapid tooling, additive fabrication, additive layer manufacturing, layer manufacturing, and freeform fabrication technologies). Initially, the AM technologies were known as Rapid Prototyping (RP) technologies since they were used for visualization and design validation purposes; however, the fast evolution of these technologies allowed the rapid manufacture (RM) of end-use parts and the rapid development of tooling. From the beginning of AM systems, more than 100 different techniques have been reported in Ref. [1]. In 2009 the American Society for Testing Materials (ASTM)

\footnotetext{
*Correspondence: hugoivanmc@uaslp.mx

Advanced Design and Manufacturing Laboratory, Facultad de Ingeniería, Universidad Autónoma de San Luis Potosí, 78290 San Luis Potosí, SLP, México
}

standardized the terminology associated with AM technologies [2].

The design and manufacture stages during a new product development process are critical because any decisions at this point can have a great impact on the final cost and quality of the product. In order to assist designers in this decision-making process, basic rules and design guidelines, known as Design for $\mathrm{X}$, have been proposed in the literature. These design guidelines are focused on manufacturability, assembly, sustainability, minimum risk, avoiding corrosion, recycling, standardization, durability, materials, maintenance, minimum cost, among others. Regarding the design for manufacturability, the existing guidelines only consider traditional manufacturing processes, such as casting, machining, forming, joining, material treatment, finishing, etc. [3, 4]. The challenge of design for AM technologies is to create quality parts that satisfy the design requirements such as functionality, geometry, mechanical properties and cost, while assuring manufacturability in AM systems. 
Several research works have focused on studying the limitations of AM technologies, such as shrinkage and layer orientation [5, 6]. In Ref. [7] six design guidelines for part cost and part weight in FDM processes were proposed. The design guidelines reported in Ref. [8] consider only three issues of FDM processes: stepping effect, knife edges and hollow parts. The influence of critical FDM parameters (layer thickness, air gap, raster angle, build orientation, road width, and number of contours) on build time, material consumption and dynamic flexural modulus, was studied in Ref. [9]. As a result, mathematical models to relate the processing conditions and the process quality characteristics were proposed and evaluated. On the other hand, geometric assessments to identify the presence of features known to cause problems such as thin sections, cusps, knife edges and part size, were proposed in Ref. [10]. Similarly, a hybrid approach to overcome size limitations and fabricate large components in AM systems was proposed in Ref. [11]. The results comprised process chains and design for manufacturing and assembly guidelines.

A general methodology to design for AM based on the capabilities and constraints of AM systems was proposed in Ref. [12]. Likewise, two design strategies for AM were proposed in Ref. [13]: a manufacturing driven design strategy to allow a substitution of manufacturing processes at a later stage of the product life cycle, and a function driven design strategy to increase the product performance. More recently, a methodology to standardize design rules from AM by decomposing fundamental geometry, process and material relationships into reusable modules, was proposed in Ref. [14]. A top-down assembly design methodology for parts and assemblies to be AM manufactured with a few or no assembly operations, was presented in Ref. [15]. The proposed methodology provides guidance into how to derive a functional architecture that is additively manufacturable. However, although several research works in the literature have focused on the Design for Additive Manufacturing (DfAM) [16-24], the development of DfAM knowledge, tools, rules, processes, and methodologies, is still one of the main technical challenges, needs and opportunities to boost the penetration and use of AM [25-31].

The aim of this paper is to review and analyse the design for Additive Manufacturing strategies, in particular for the FDM process. From this review and analysis, a new comprehensive set of DfAM strategies are proposed based on the operation principle, materials, capabilities and limitations of existing FDM technologies, and on the analysis of existing studies in the literature. The proposed design and manufacturing rules consider the main technical limitations and problems of current FDM systems, which are susceptible to evolve and change with time.

\section{Additive Manufacturing Technologies}

Additive manufacturing is the process of adding material to produce physical objects from their digital model data [32]. Unlike traditional manufacturing processes, where material is removed to generate a part, most of AM techniques are based on an additive process, where components are built up gradually layer by layer [33]. The general methodology to produce a component in AM systems is shown in Figure 1. From their origins, AM technologies have been used for creating models and prototypes (Rapid Prototyping), end-use parts (Rapid Manufacturing), and long-term tools for mass production of parts (Rapid Tooling) [29, 34]. According to the operation principle AM technologies can be comprehensively classified into four main categories [1]: additive, subtractive, forming and hybrid processes. More recently, the ASTM grouped the complete range of AM technologies into seven categories: binder jetting, direct energy deposition, material extrusion, material jetting, powder bed fusion, sheet lamination, and vat photopolymerization [32].

\section{Design for Additive Manufacturing (DfAM)}

According to Ref. [29], the objectives and goals of DfAM comprise the three levels of abstractions of traditional Design for Manufacturing and Assembly (DfMA): 1) to offer tools, techniques and guidelines to adapt a design to a given set of downstream manufacturing constraints; 2) to understand and quantify the effect of the design process on manufacturing (and viceverse) in order to improve the performance of the manufacturing system and product quality; and 3) to know the relationship between design and manufacturing and its impact on the designer, the design process and the design practice. However, although the definition and goals of DfMA may be applicable for AM technologies, the design knowledge,

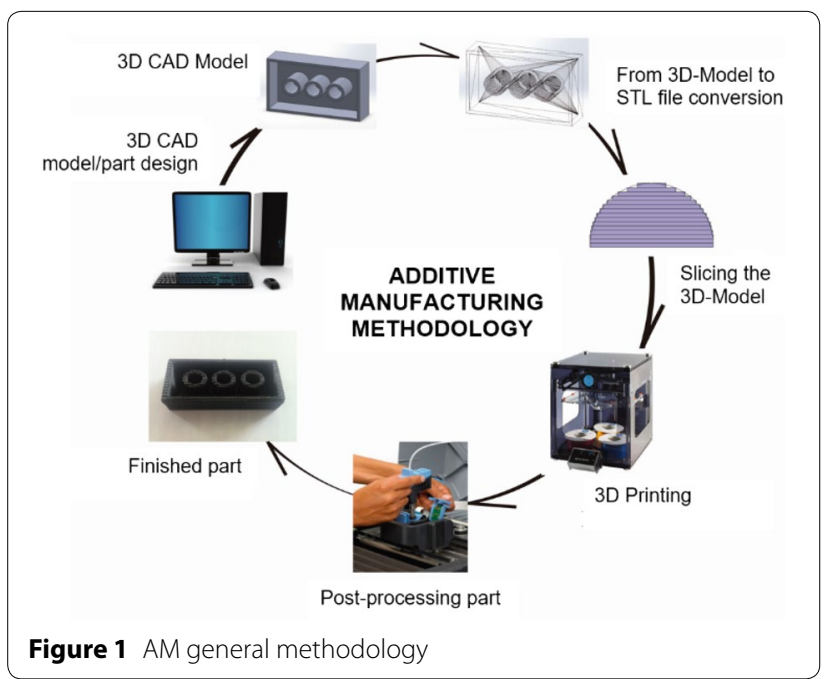


tools, rules, processes, and methodologies will be substantially different for DfAM [29]. In fact, the development of such knowledge, tools, rules, processes, and methodologies for AM has been identified as one of the main technical challenges that have prevented the overall penetration of AM in industry [21, 27-29]. Being aware of the limitations and capabilities of AM can help designers to generate components suitable for AM production $[4,12,13,26]$. The unique capabilities of AM comprise shape complexity, material complexity, functional complexity, hierarchical complexity, mass customization, product personalization, and production decentralization [35-37]. The designers' challenge is to use these exceptional characteristics to create a functional product for the user and an added value product for the manufacturer. Thus, the aim of DfMA is to assist designers in the creation of quality and cost-effective parts to satisfy functional needs, while ensuring manufacturability in AM systems.

\section{Design and Manufacturing Strategies for FDM}

The material extrusion AM processes are those in which the material is selectively dispensed through a nozzle or orifice. These processes are characterized by a pre-heating chamber that raises the material temperature to the melting point so that it can flow through a nozzle in a controlled manner [16]. AM extrusion techniques comprise Fused Deposition Modelling (FDM), Bioplotting, Fused Deposition of Ceramics (FDC), Extrusion Free Forming (EFF), Contour Crafting (CC), Shaped Deposition Manufacture (SDM), Ballistic Particle Manufacture (BPM), among others. The FDM process is one of the most widely used AM technique because of its several advantages, such as low technology and maintenance costs, low material cost, wide range of materials available, easy to operate, low temperature operation, compact design, office friendly, among others [38]. In the
FDM process the parts are created layer by layer. Each layer is created by depositing semi-liquid material on a fixtureless platform and in a temperature-controlled environment [39, 40]. The conventional FDM process can produce parts from thermoplastic materials such as ABS (Acrylonitrile-Butadiene-Styrene) and PLA (Polylactic Acid); however, variants of this process consider the use of ceramics, digital materials and other composite materials.

Although AM technologies have exceptional capabilities, they still have some limitations and drawbacks that prevent designers from creating unlimited parts. These limitations are related to the operating principle, production speed, part geometry, part size, materials, etc. According to Ref. [16], there are some key characteristics that are common to material extrusion processes: 1 ) loading of material, 2) liquefaction of material, 3) application of pressure to move the material through the nozzle, 4) extrusion mechanism, 5) plotting according to a predefined path, 6) bonding of the material to itself or secondary build materials, and 7) addition of supporting structures to enable complex geometries. From the analysis of these characteristics and technical capabilities of commercial systems, the main advantages and disadvantages of FDM systems were identified and are summarized in Table 1. Consequently, design and manufacturing strategies for FDM systems are identified, analysed and divided into four main groups: strategies for geometry, strategies for quality, strategies for material and strategies for sustainability.

\subsection{Strategies for Geometry}

In theory, any shape or geometry can be easily created in AM systems. However, the geometrical freedom of current FDM technologies is still fairly limited by the size of the part, the need to provide and remove support

Table 1 General advantages and disadvantages of FDM systems

\begin{tabular}{ll}
\hline Advantages & Disadvantages \\
\hline Geometry free fabrication & Low speed production \\
Low technology and materials costs & Limited accuracy and resolution \\
Easy to operate and material handling & Limited surface finish \\
Low temperature operation & Staircase effect, distortion, shrinkage and warping \\
Low production and maintenance costs & Support structures are required for complex geometries and features \\
Low process toxicity & Removal of support structures \\
Low power consumption & Limited range of materials \\
Multiple material systems are available & Limited mechanical strength of parts \\
Colour parts can be generated & Limited building-volume or workspace \\
Compact design and office-friendly & \\
Low noise operation and dust emissions & \\
Low odour generation & \\
Mass customization & \\
Product personalization & \\
\hline
\end{tabular}


structures, the complexity and size of small features, etc. [34]. Therefore, geometry limitations of FDM systems must be considered as follows.

\subsubsection{Support Structures, Cavities \& Overhangs}

Support structures are an array of thin ribs used to rigidly attach the part to the construction platform and avoid the collapse of the part under construction, in particular cavities and overhangs features, Figure 2. The lack of support structures may lead to the distortion of the part, causing geometrical and dimensional errors; for instance, overhangs may affect the surface flatness because of distortion. However, support structures are difficult to be removed from beneath features or inside internal cavities. The removal or braking away processes of support structures may also damage small features of the part [41]. According to Ref. [21], the length for overhangs in FDM must be kept under $1.8 \mathrm{~mm}$ in order to avoid the falling out of the filaments due to their low stiffness when the overhang becomes longer than $1.8 \mathrm{~mm}$. This limitation can be also used to define the separation or gap among support structures. Moreover, gaps between combined elements must be designed with a minimum gap height of $0.4 \mathrm{~mm}$ in order to achieve the smallest possible dimensional deviations [21].

\subsubsection{Part Size}

Typical build sizes for midrange commercial FDM systems are in the range of $200 \mathrm{~mm}$ to $300 \mathrm{~mm}$. The largest

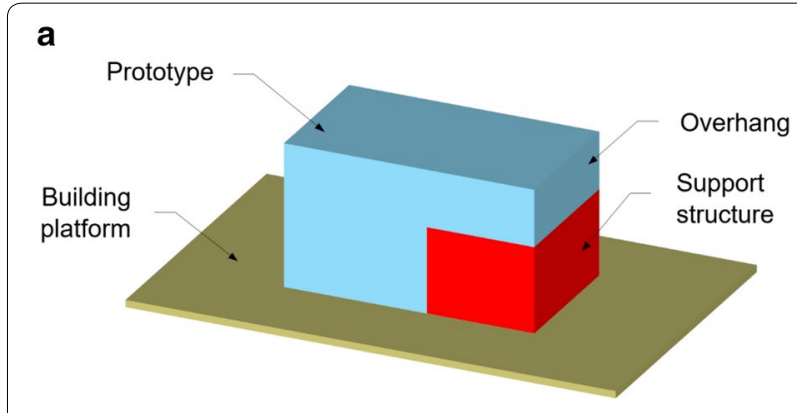

b

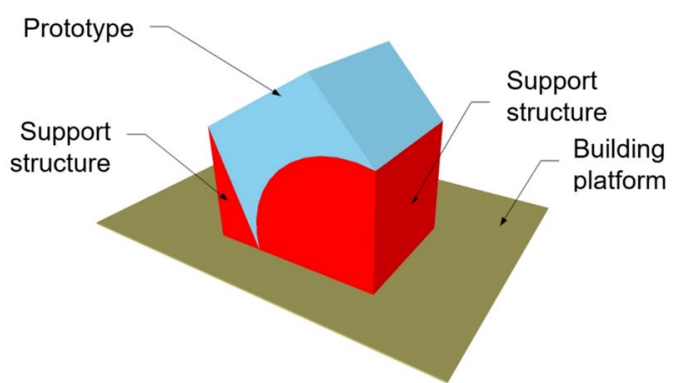

Figure 2 Support structures: (a) structure to support overhangs, (b) support structures to link the part to the build platform
FDM system commercially available has a build volume of $1000 \times 800 \times 500 \mathrm{~mm}$. Consequently, designers must consider the build size limitation when designing a component intended to be fabricated by FDM. If the part is larger than the build size of the FDM system, it could be fabricated by combining FDM with other manufacturing process (hybrid approach) [11]; or it could be carefully subdivided into smaller part sections to be fabricated in the FDM system [10]. Once all the part sections are fabricated, they can be assembled and bonded together to complete the part. In general, a part can be subdivided into smaller sections by an array of orthogonal planes, but the resulting subcomponents may have geometries that are difficult to produce on FDM systems. Therefore, the decomposition process must consider the size and shape capabilities of the FDM system in order to generate part subsections that are suitable for fabrication.

\subsubsection{Thin Sections}

Parts with excessively thin sections are difficult to produce in FDM systems because these sections may break or distort during fabrication. The ability of FDM systems to produce thin sections depends on the layer thickness. The use of an incorrect layer thickness can cause breakable walls and geometry distortion. The minimum wall thickness that can be produced with a specific value of layer thickness in dispensing processes, are as shown in Table 2. The generation of narrow holes with close tolerances is also a complex task for most FDM systems because these features tend to distort. In this case a postprocessing step is required to obtain the final dimensions and tolerances. To avoid the risk of damage during handling, a wall thickness between 1 to $1.5 \mathrm{~mm}$ is recommended [42], which depends on the layer thickness. Existing commercial FDM systems allow layer thicknesses as fine as 16 microns.

\subsubsection{Geometrical Features}

Geometrical features, such as fillets, sharp edges, sharp angles, narrow holes, tangential transitions, etc., can be easily produced on FDM systems. However, all FDM processes have limitations in terms of accuracy, resolution and repeatability. Since in FDM systems all nozzles are circular, it is impossible to draw sharp external and

Table 2 Minimal wall thickness in dispensing processes

\begin{tabular}{ll}
\hline Layer thickness $\mathbf{m m}$ (in) & $\begin{array}{l}\text { Minimal wall } \\
\text { thickness } \mathbf{~ m m} \\
\text { (in) }\end{array}$ \\
\hline $0.18(0.007)$ & $0.71(0.028)$ \\
$0.25(0.01)$ & $1.02(0.04)$ \\
$0.33(0.013)$ & $1.32(0.052)$ \\
\hline
\end{tabular}


internal edges or corners; there will be a radius equivalent to that of the nozzle at any corner or edge [16]. The dimensional accuracy in FDM systems depends on several factors such as the system resolution, layer thickness, nozzle diameter, part geometry, build parameters, part orientation, material properties and deviations, distortion, warping, and shrinkage [43]. The typical accuracy values of commercially available FDM systems are in the range of $0.100 \mathrm{~mm}$ to $0.300 \mathrm{~mm}$; however, there are some systems capable of generating features as small as 16 micron. However, small features may distort or break during fabrication or during the removal of support structures because of their poor structural strength. Therefore, features must not be too small, too closely spaced, or with extremely geometric accuracy and tolerances beyond the system's capabilities. According to Ref. [21], sharp edges cannot be manufactured without form defects; the size of the material filament limit the minimal dimensions of edges. Superior form accuracy and removability of support structures can be obtained with rounded and blunted edges.

\subsubsection{Build Orientation}

Determining the optimal build orientation of a part is an essential task in FDM systems. The build orientation may affect the surface finish and geometric tolerances, mechanical properties, use of support structures, material consumption, and build time and costs. Surface finish, particularly the staircase effect, depends on the layer thickness and varies according to the surface and part orientation. The amount of support structures required to build a part depends on the part orientation and affects the material use, production time and part cost [44-46]. Some methods to find the optimal part orientation in AM systems have been proposed and studied in the literature. A method to obtain the optimal build orientation by minimizing the surface contact with support structures was described in Ref. [47]. Also, a method to orientate the part to reduce the construction time and optimize the build space was suggested in Ref. [48]. A procedure to calculate the number of layers in different directions in order to find the optimal orientation in terms of building time was reported in Ref. [49]. Similarly, an algorithm to minimize the build direction was reported in Ref. [50]. An algorithm to orientate the part and reduce the staircase effect was proposed in Ref. [51]. More recently, the design principle early determination of the part orientation, which states that the orientation should be determined before the final design of the part begins, was proposed in Ref. [52]. A new process to determine the build orientation based on dividing the concept design of the part into several design elements, and analyse them separately to determine their best orientation and the global orientation of the part, was envisaged in Ref. [52]. A functionality-based part orientation methodology for AM fabrication of assembled products was presented in Ref. [53]. The methodology focuses on the assembly features while considering the part orientation. According to Ref. [9], the build orientation has a marginal effect on build time, and it has a little effect on material consumption and flexural modulus. The build orientation that leads to the minimum number of layers is the desirable orientation of the part not only for reducing the build time and material consumption, but also to achieve good surface roughness and mechanical properties along with a higher dimensional accuracy [9].

The aim of an optimal build orientation selection is to improve surface finish, increase part strength in a specific direction, reduce support material, minimize build time and maximize the geometric accuracy [54]. However, there are several factors that must be considered when selecting the build orientation in FDM systems [9, 51, 55-57]:

- Part height and building time. Since the time required to create a layer is essentially the same regardless of the layer complexity, the build time depends directly on the number of layers, i.e., the build height of the part.

- Surface quality. The build orientation determines the part surfaces that will suffer the staircase effect.

- Surface support. The part stability during construction is affected by the surface area on which the part is supported on the building platform, i.e., build orientation.

- Mechanical properties. The part has orthotropic mechanical properties that depend on the layer and build orientation.

- Sloped surfaces. The staircase effect varies with the surface inclination, which is dependent on the build orientation.

\subsubsection{Path Planning}

Path planning refers to the process of planning the tool trajectories to produce a part in an FDM system. Two types of paths are considered: internal and external paths. Internal path planning considers the strategy to fill the interior of the layers. On the other hand, external path planning comprises the generation of the tool path trajectories to create the layer contours. Path planning affects the mechanical properties, material usage, cost, weight and inertia of the fabricated part. FDM processes require internal path planning to define the strategy to fill the entire volume of the part [51, 58-61]. The internal path planning comprises the infill percentage 
(contrary air gap), filling pattern and layer orientation process parameters. Several investigations have been conducted to evaluate the influence of these process parameters on the mechanical properties of FDM parts [42, 62-68]. The results have shown that the structural properties are directly influenced by the infill percentage and the infill pattern. Spiral and curved filling paths have been proposed in order to reduce the anisotropic effect and improve the mechanical properties of parts [69]. Regarding the external paths, the results have shown that the number of contours has also a direct effect on the mechanical properties of FDM parts. In addition, the effect of the raster angle and the number of contours on the build time, material consumption and flexural modulus was evaluated in Ref. [9]. The results evidenced that the raster angle has a marginal effect on build time and flexural modulus but has no effect on the material consumption; whereas the number of contours has a direct effect on the build time, material consumption and flexural modulus. Figure 3 shows some of the filling patterns used in the FDM process.

Thus, the proposed DfAM strategies concerning part geometry are shown in Table 3.

\subsection{Strategies for Quality}

Distortion, shrinkage and warping are present in FDM parts. If these defects are not considered at the design and manufacturing stages, the accuracy and quality of the part could be reduced since the small features, surface finish, dimensional tolerances and shape tolerances may be affected.

\subsubsection{Distortion, Shrinkage \& Warping}

The quality and dimensional accuracy of FDM parts are affected by distortion, shrinkage, and warping, which are known to be caused by the internal stresses generated during fabrication. The internal stresses depend on the volume shrinkage during the cooling period from the glass transition temperature to the building room temperature. According to Ref. [70], the largest warping deformation (d) of FDM parts depends on the number of layers $(n)$, the section length of the part $(L)$, the material shrinking coefficient $(\alpha)$, the thickness of layer $(\Delta s)$,

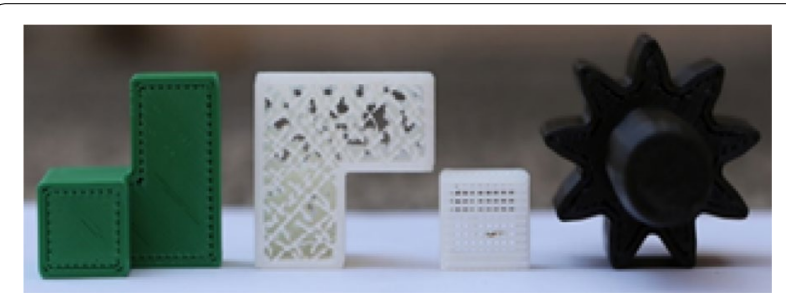

Figure 3 Filling path strategies used in an FDM process the build room temperature $\left(T_{e}\right)$, and the glass transition temperature $\left(T_{g}\right)$, as follows:

$$
\delta=\frac{n^{3} \Delta s}{6 \alpha\left(T_{g}-T_{e}\right)(n-1)}\left\{1-\cos \left[\frac{3 \alpha L}{n \Delta s}\left(T_{g}-T_{e}\right) \frac{n-1}{n^{2}}\right]\right\} .
$$

The experimental results reported in Ref. [70] showed that warping of FDM parts decreases with $n$ increasing, $L$ decreasing, $\Delta s$ decreasing, $\alpha$ decreasing, and $T_{e}$ increasing.

\subsubsection{Surface Finish}

The surface finish can be defined in terms of the surface roughness value $(R a)$. Since FDM systems are based on a layer by layer additive process, the staircase effect is present and affects the part surface finish [56]. The staircase effect depends on the surface inclination and the layer thickness $[44,45]$. The average surface roughness $(R a)$ can be estimated by the following equation [48]:

$$
R a=\frac{L}{2}\left|\frac{\cos (\theta-\phi)}{\cos \phi}\right|,
$$

where $L$ is the layer thickness, $\theta$ is the surface angle, and $\phi$ is the profile surface angle, as shown in Figure 4. The surface finish in FDM depends not only on the part orientation, layer thickness, layer orientation, and surface angle, but also on the material, intricate features, distortion, shrinkage, and warping.

\subsubsection{Stability and Post-Processing}

The stability of a part during and after its production in FDM systems must be ensured to preserve its quality and geometric characteristics. Therefore, factors, such as support structures, building orientation, environmental conditions, building material, and post-processing, are important for part stability. Parts produced by FDM are dimensionally stable, unlike parts made by vat photopolymerization processes, which are vulnerable to shrinkage and creep after fabrication. However, FDM parts made of polymers are affected by environmental agents, such as heat, UV radiation, moisture and chemical reactions, causing instability, material aging, layer bonding reduction, and tolerance and geometry deviations. On the other hand, post-processing comprises the removal of support structures, the improvement of surface finish, and the enhancement of dimensional accuracy (mainly in features) to ensure part usability and stability. These postprocessing operations are usually required in parts fabricated by FDM.

Thus, the proposed DfAM strategies concerning part quality are shown in Table 4. Since the part geometry strategies shown in Table 3 are also related to the 


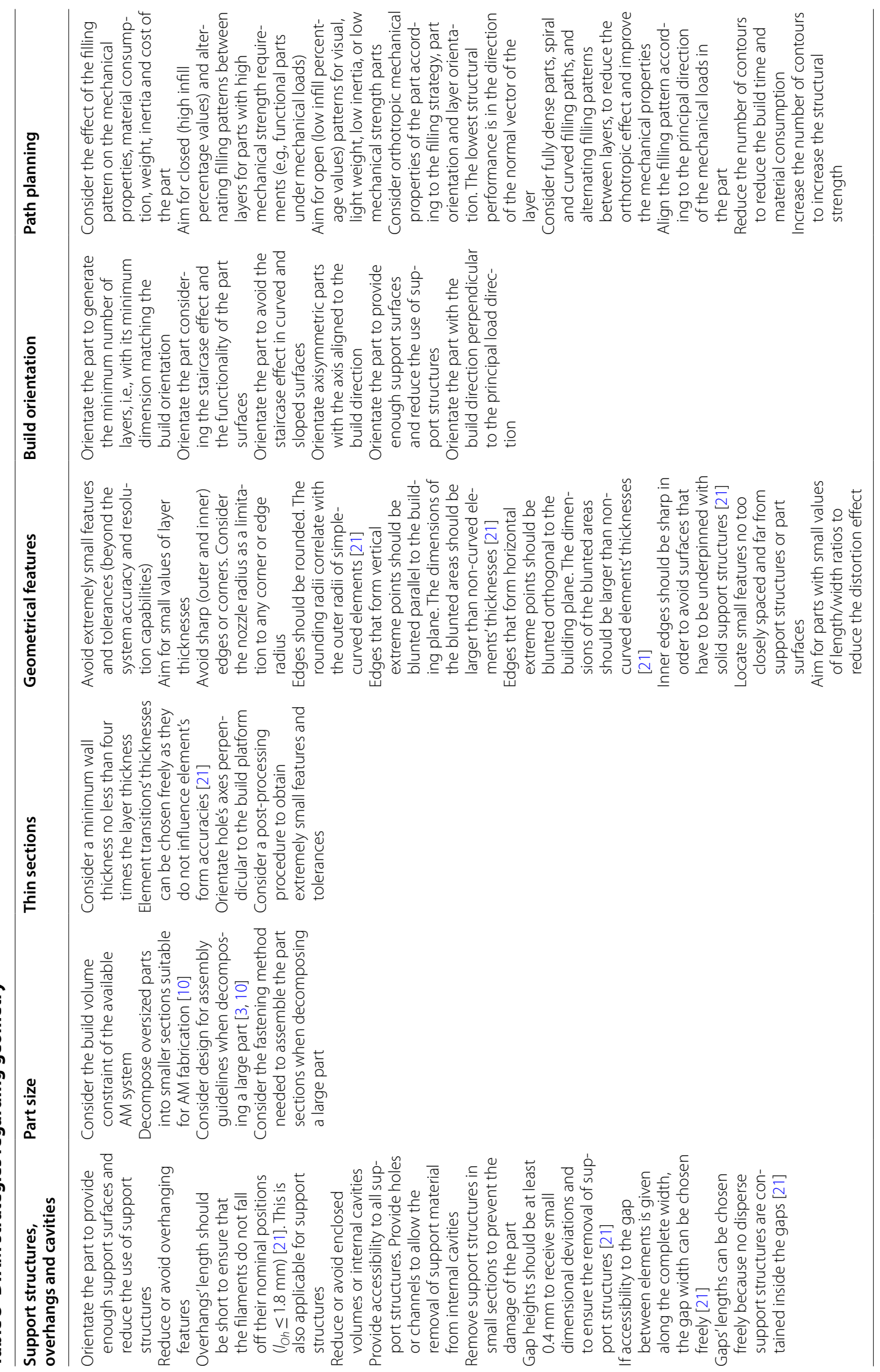




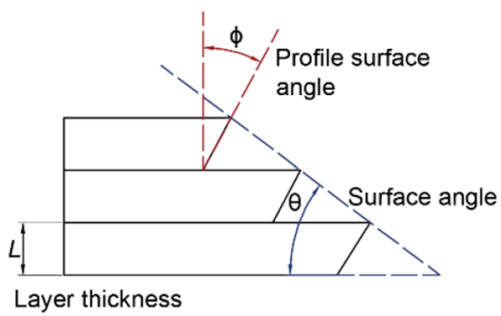

Figure 4 Parameters to calculate the surface roughness in AM systems

geometrical quality of the part, they must be also considered to assure the quality of the FDM part.

\subsection{Strategies for Material}

At the design stage, some characteristics of the material such as mechanical properties, manufacturability, cost, availability and disposal, must be considered to select the appropriate material [4].

\subsubsection{Type of Material}

At the present time, the range of materials available in AM technologies is large and includes polymers, metals, ceramics, and organics [46, 71]. Moreover, some AM systems can produce parts with two or more different materials. Figure 5 attempts to summarize the range of materials available in current AM technologies. In the case of commercial FDM systems, polymeric materials, such as ABS, PLA, PC, PP, PPSF/PPSU, Nylon, ASA, elastomers and wax, are available. Table 5 presents a general overview of the mechanical strength (tensile strength ultimate) ranges of current commercial AM materials and processes, which has been generated from the analysis of the AM manufacturers' accessible data and the study presented in Ref. [71].

\subsubsection{Mechanical Properties}

One of the main characteristics to be considered when designed a part for AM is the mechanical properties of the material, particularly the mechanical strength. Several investigations have been conducted in order to determine the influence of the process parameters on the mechanical properties of AM components [38, 40, $65,72-80]$. The results have shown that the mechanical properties of an AM part depend not only on the material properties, but also on the process parameters used when fabricating the part. In the case of the FDM process, the process parameters that affect the mechanical strength are the build orientation, layer thickness, infill percentage and filling pattern [42, 62-68]. The infill percentage and pattern are two of the most influencing parameters; the larger the infill percentage is, the larger the strength of the part. Spiral and curved filling paths have been proposed in order to reduce the anisotropic effect and improve the mechanical properties of FDM parts [69]. One major weakness of FDM parts is that they exhibit reduced strength along the build direction caused by the bonding strength between layers. The mechanical properties of FDM parts also depend on the number of contours used to fabricate the part; the larger the number of contours is, the greater the part strength. The layer thickness has a small influence on the mechanical strength; the smaller the layer thickness is, the greater the part strength. A mathematical model to estimate the dynamic flexural modulus $(D F M)$ as a function of the

\section{Table 4 DfAM strategies regarding quality}

\begin{tabular}{|c|c|c|}
\hline Shrinkage, distortion and warping & Surface finish & Stability and post-processing \\
\hline $\begin{array}{l}\text { Use small values of layer thicknesses to } \\
\text { reduce the distortion, shrinkage, and } \\
\text { warping effects } \\
\text { Aim for parts with small values of length } \\
\text { to width ratios to reduce the distortion } \\
\text { effect. If necessary, divide long parts into } \\
\text { several shorter parts } \\
\text { Avoid long thin parts as far as possible to } \\
\text { reduce the distortion, shrinkage, and } \\
\text { warping effects } \\
\text { Select material depositing directions along } \\
\text { the short side of the part to reduce warp- } \\
\text { ing } \\
\text { If possible, use materials with low shrinking } \\
\text { coefficients and glass transition tempera- } \\
\text { tures } \\
\text { Increase the build room temperature to } \\
\text { lower internal stresses and warping }\end{array}$ & $\begin{array}{l}\text { Orientate the part considering the staircase effect and the } \\
\text { functionality of the part surfaces } \\
\text { Estimate the surface roughness based on Eq. (2) and com- } \\
\text { pare it with the design requirements. Adjust the process } \\
\text { parameters if necessary } \\
\text { Use small values of layer thickness and surface angles close } \\
\text { to } 90^{\circ} \text {, to reduce the surface roughness and the staircase } \\
\text { effect } \\
\text { Orientate the part to avoid the staircase effect in curved and } \\
\text { sloped surfaces } \\
\text { Consider post-processing operations to improve the surface } \\
\text { finish and eliminate the staircase effect. Conventional } \\
\text { techniques, such as sanding, polishing, grinding, can be } \\
\text { used }\end{array}$ & $\begin{array}{l}\text { Orientate the part to provide enough } \\
\text { support surfaces and reduce the use of } \\
\text { support structures } \\
\text { Orientate the part with the largest surface } \\
\text { area laying on the building platform } \\
\text { Remove support structures in small sec- } \\
\text { tions to prevent the damage of the part } \\
\text { Provide additional coating to parts to } \\
\text { ensure environmental resistance } \\
\text { Provide special coating to functional parts } \\
\text { to improve part integrity, stability and } \\
\text { strength, if necessary } \\
\text { Ensure total adhesion or binding of the } \\
\text { material and layers in the part }\end{array}$ \\
\hline
\end{tabular}


FDM process parameters was proposed in Ref. [9] as follows: thermal, dynamic and visual [26]. To achieve the desired properties of the FDM part, structures such as handles,

$$
\begin{aligned}
D F M(\mathrm{MPa})= & -1992.089+2507.582 A-2404.225 B-0.732 C \\
& +0.0519 D+10168.137 E+6.090 F-688.983 A B \\
& -1725.895 A E+1818.298 B E+88.567 B F-7.228 E-003 C D \\
& -2924.348 A^{2}+1175.176 B^{2}+9.988 \times 10^{-3} C^{2}-9910.801 E^{2},
\end{aligned}
$$

where $A, B, C, D, E$ and $F$, are the layer thickness, air gap, raster angle, part road width, build orientation and number of contours process parameters, respectively. This model is subject to the following rules: $0.127 \mathrm{~mm} \leq A \leq 0.3302 \mathrm{~mm}, \quad 0 \mathrm{~mm} \leq B \leq 0.5 \mathrm{~mm}$, $0^{\circ} \leq C \leq 90^{\circ}, 0^{\circ} \leq D \leq 90^{\circ}, 0.4572 \mathrm{~mm} \leq E \leq 0.5782 \mathrm{~mm}$, and $0 \leq F \leq 10$. From this model it is observed that all the process parameters affect the flexural modulus, but the two most influential parameters are the air gap (the opposite of infill percentage) and the number of contours. The smaller the air gap, the larger the flexural modulus; whilst the larger the number of contours, the larger the flexural modulus.

More recently, the effect of the process parameters on the wear behaviour of FDM PC-ABS components was investigated in Ref. [81]. As a result, the following mathematical model was proposed:

$$
\begin{aligned}
S W R\left(\mathrm{~mm}^{3} / \mathrm{Nm}\right)= & 0.000002+0.000004 A \\
& -0.000000 C+0.000000 D \\
& -0.000000 F+0.000000 F^{2},
\end{aligned}
$$

where SWR is the sliding wear resistance, and $A, C, D$ and $F$ are the layer thickness, raster angle, build orientation, and number of contours process parameters, respectively. The $S W R$ is defined as follows:

$$
S W R=\frac{\Delta V}{F \times S},
$$

where $\Delta V\left(\mathrm{~mm}^{3}\right)$ is the volume loss of the sample, $F$ is the applied load $(\mathrm{N})$, and $S$ is the sliding distance $(\mathrm{m})$. According to this wear model, the raster angle, layer thickness, build orientation and number of contours are the most influential parameters affecting the wear performance of FDM parts; the wear rate decreases as the layer thickness and build orientation decrease and the air gap and raster angle increase [81].

The use of structures at three different levels (micro, meso and macro structures) have been proposed in the literature in order to optimize the design and performance of AM components [26, 82-87]. The performance is commonly defined in terms of the design requirements, such as weight, stiffness, strength, compliance,

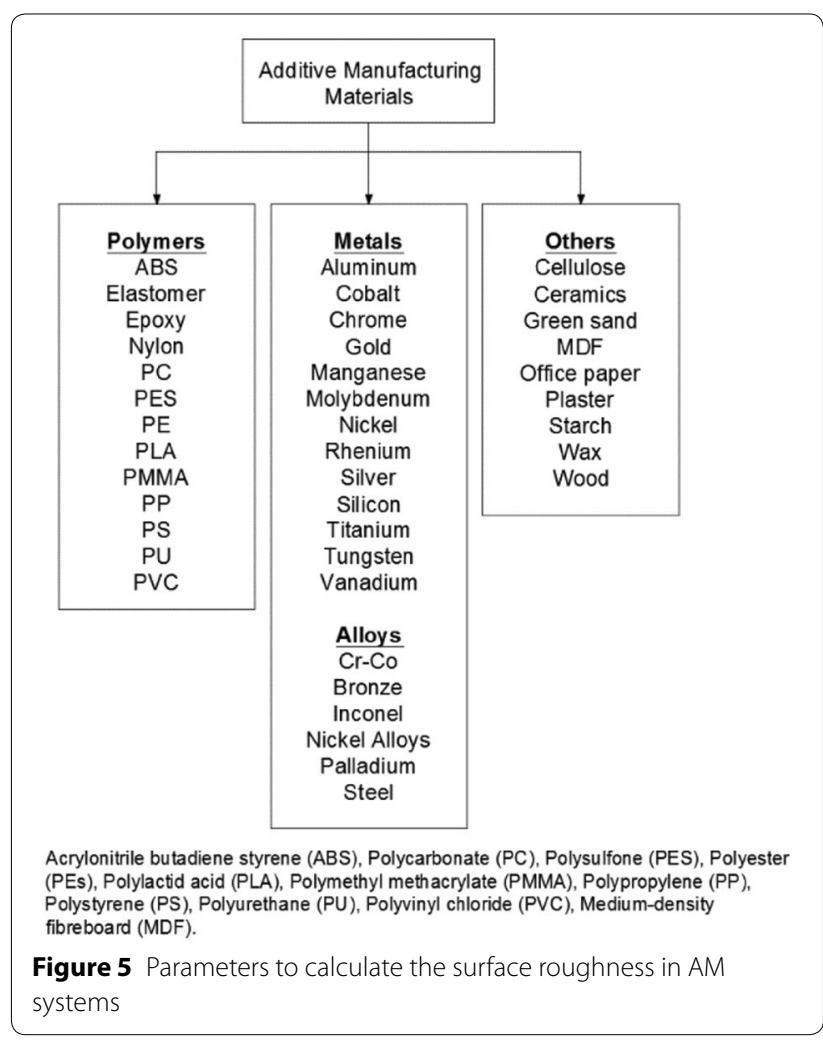

Table 5 Mechanical strength of commercial AM materials

\begin{tabular}{ll}
\hline Material group or AM process & $\begin{array}{l}\text { Mechanical strength } \\
\text { (ultimate tensile strength) } \\
\text { (MPa) }\end{array}$ \\
\hline Polymers & $1.5-150$ \\
Metals & $150-500$ \\
Alloys & $>500$ \\
FDM process & $36-71.64$ \\
SLS process & $19-470$ \\
SL, SGC and MJM processes (Photopoly- & $22-79$ \\
mers) & $1.46-60.3$ \\
MJM and BPM processes (Thermopoly- & \\
mers) & $9-24$ \\
3DP process & 26 \\
LOM process (paper material) &
\end{tabular}


ribs, cellular and lattice, are added and optimized to reduce weight and material usage. In general, these structures are only possible to be created in AM systems.

Considering the wide range of materials and properties of existing FDM systems, and the influence of geometry and process parameters on the mechanical properties of FDM parts, DfAM strategies regarding material and mechanical properties are proposed as shown in Table 6.

\subsection{Strategies for Sustainability}

Design for sustainability consider the creation of products that maximize their economic and social impact and minimize harmful environment effects. Thus, the AM strategies for sustainability must consider the design of durable parts, the use of recycled materials, the use of high-efficiency manufacturing processes, the reduction of toxic materials, and a deep link between the product and the user. Products that meet these criteria usually have longer life and reduced negative impact on the environment. AM technologies allow designers to generate customized products with practically unlimited shapes for high value applications, such as medical (e.g., hearing aids, prosthesis and medical implants), sports, aviation, automotive, marine, among others. AM systems can generate products that satisfy the triple bottom line requirements: economy, environment and society; making sustainable products [88].

\subsubsection{Part Cost}

The cost of a part fabricated in FDM depends on the material consumption, material cost, build time, energy use, system's cost, and post-processing work. The material consumption and cost depend on the part volume and the material unit cost. Some parts may require support structures and therefore the additional material cost of these structures must be also considered. Build time also affects the part cost because it increases the energy consumption and the use of the system. Since the build orientation affects the build time, support structures, and cost, the build orientation must be selected considering a compromise among these three effects. The following mathematical model to estimate the Feedstock Material Consumption $(F M C)$ in FDM was proposed in Ref. [9]:

$$
\begin{aligned}
F M C\left(\mathrm{~cm}^{3}\right)= & 0.972-0.545 A-2.423 B+6.301 \times 10^{-4} D \\
& +3.866 E+0.025 F+0.332 A B-1.439 A E \\
& +1.185 B E+0.113 B F-0.049 E F+1.888 A^{2} \\
& +1.088 B^{2}-7.410 \times 10^{-6} D^{2}-3.248 E^{2}
\end{aligned}
$$

where $A, B, C, D, E$ and $F$, are the layer thickness, air gap, raster angle, part road width, build orientation and number of contours process parameters, respectively. This model is subject to the following rules: $0.127 \mathrm{~mm} \leq A \leq 0.3302 \mathrm{~mm}, \quad 0 \mathrm{~mm} \leq B \leq 0.5 \mathrm{~mm}$, $0^{\circ} \leq C \leq 90^{\circ}, 0^{\circ} \leq D \leq 90^{\circ}, 0.4572 \mathrm{~mm} \leq E \leq 0.5782 \mathrm{~mm}$, and $0 \leq F \leq 10$. From this model it is observed that the most influential parameters on the material consumption are the air gap and the number of contours. The larger the air gap, the smaller the material consumption;

\begin{tabular}{|c|c|}
\hline Material & Mechanical properties \\
\hline $\begin{array}{l}\text { Define the material requirements of the part based on its application and } \\
\text { functionality } \\
\text { Consider the limited range of existing materials (polymeric materials): ABS, } \\
\text { PLA, PC, PP, PPSF/PPSU, Nylon, ASA, elastomers and wax } \\
\text { Consider the mechanical properties of existing AM materials (Table 5) } \\
\text { Consider an experimental assessment of the mechanical properties of the } \\
\text { unprocessed material } \\
\text { Consider the use of multi-material AM systems if necessary }\end{array}$ & $\begin{array}{l}\text { Consider the effect of process parameters on the mechanical properties, } \\
\text { weight, and inertia of the part, Eqs. (3) and (4) } \\
\text { Use high infill percentage values (low air gap values) and alternating filling } \\
\text { patterns for high mechanical strength parts (e.g., functional parts under } \\
\text { mechanical loads) } \\
\text { Use low infill percentage values (high air gap values) and open filling pat- } \\
\text { terns for visual, light weight, low inertia, or low mechanical strength parts } \\
\text { Use small layer thickness values for high mechanical strength parts (e.g., } \\
\text { functional parts under mechanical loads) } \\
\text { Consider anisotropic mechanical properties of the part according to the } \\
\text { filling strategy, part orientation and layer orientation } \\
\text { Consider fully dense parts, and spiral, curved and alternating infill patterns } \\
\text { to reduce the anisotropic effect } \\
\text { Consider the use of structures at different scales (micro, meso and macro } \\
\text { structures), such as handles, ribs, cellular and lattice, to achieve the } \\
\text { desired mechanical properties and optimise the part design } \\
\text { Align the infill pattern and layer according to the principal direction of the } \\
\text { mechanical load in the part } \\
\text { Reduce layer thickness and build orientation, and increase air gap and } \\
\text { raster angle to increase the wear resistance of the part [81] } \\
\text { Consider an experimental assessment of the mechanical properties of the } \\
\text { part after its fabrication }\end{array}$ \\
\hline
\end{tabular}
whereas the smaller the number of contours, the smaller the material consumption.

\section{Table 6 DfAM strategies regarding material and mechanical properties}




\subsubsection{Energy Consumption}

Energy consumption in AM systems depends on the percentage of utilizing the machine (build time), the material consumption and the part orientation. According to Ref. [89], the FDM process has the lowest ecological impact per part over the $\mathrm{CNC}$ and polyjet processes. In contrast, an investigation reported in Ref. [90] revealed that $\mathrm{CNC}$ machining has less ecological impact than the SLS and FDM processes. An investigation to analyse the production time and energy consumption in terms of the building orientation and internal filling in FDM, was presented in Ref. [91]. A computation tool to assess the product's environmental impact was developed and the results showed that the part orientation affects directly the energy consumption during the production process, and that the material consumption is also critical for the product end-of-life disposal. Moreover, to minimize the energy environmental impact, it is essential to reduce the non-productive time of the extrusion system and reduce the amount of productions to dilute the pre-heating between productions [91]. Since the build orientation (which defines the number of layers) and material consumption affect the build time, the energy consumption and environmental impact depend directly on the build time; the larger the build time, the greater the energy consumption. The following mathematical model to estimate the Build Time (BT) in FDM was also proposed in Ref. [9]:

$$
\begin{aligned}
B T(\min )= & 21.616-129.180 A-3.732 B+0.022 C \\
& +0.056 D+4.395 E+0.777 F+11.039 A B \\
& -1.26 A F-0.073 D E-0.627 E F+224.347 A^{2} \\
& -2.307 \times 10^{-4} C^{2}-1.721 \times 10^{-4} D^{2},
\end{aligned}
$$

where $A, B, C, D, E$ and $F$, are the same FDM process parameters defined previously. In this case, the build time

\begin{tabular}{|c|c|c|}
\hline Part cost & Energy consumption & Environmental resistance \\
\hline $\begin{array}{l}\text { Aim for low-cost and recyclable FDM } \\
\text { materials } \\
\text { Consider the effect of the air gap on the } \\
\text { material use, build time and part cost, } \\
\text { Eqs. (6) and (7) } \\
\text { Aim for open patterns (high air gap val- } \\
\text { ues) for visual, light weight, low inertia, } \\
\text { or low mechanical strength parts } \\
\text { Orientate the part to reduce the use of } \\
\text { support structures } \\
\text { Consider the additional energy and cost } \\
\text { of the post-processing work or treat- } \\
\text { ment, if needed }\end{array}$ & $\begin{array}{l}\text { Aim to reduce the build time by } \\
\text { minimizing the number of contours } \\
\text { and layers, and by increasing the layer } \\
\text { thickness and air gap, Eq. (7) } \\
\text { Orientate the part with its minimum } \\
\text { height matching the build orientation } \\
\text { Reduce the amount of productions } \\
\text { to dilute the pre-heating between } \\
\text { productions } \\
\text { Reduce the non-productive time of the } \\
\text { extrusion system }\end{array}$ & $\begin{array}{l}\text { Ensure total adhesion or binding of the material and layers in the } \\
\text { part } \\
\text { Provide additional coating to parts in order to increase their } \\
\text { environmental resistance } \\
\text { Provide protective coating to parts that will be exposed to aggres- } \\
\text { sive environments, corrosion, chemicals, humidity, UV radiation } \\
\text { or high temperatures } \\
\text { Avoid the exposure of plastic parts to high temperatures (typically } \\
\text { over } 50^{\circ} \mathrm{C} \text { ) }\end{array}$ \\
\hline
\end{tabular}
is greatly influenced by the layer thickness and the number of contours.

\begin{tabular}{|c|c|}
\hline Design for AM guidelines & Design and fabrication decisions \\
\hline $\begin{array}{l}\text { Support structures, cavities } \\
\text { and overhangs }\end{array}$ & $\begin{array}{l}\text { To reduce cost, material use, weight and production time, a hollow structure was considered, providing access to the } \\
\text { support structures for their removal }\end{array}$ \\
\hline Part size & $\begin{array}{l}\text { Since the dimensions of the breast implant are smaller than the system workspace, no part size problems were envis- } \\
\text { aged }\end{array}$ \\
\hline Thin sections & $\begin{array}{l}\text { In order to reduce the production time and increase the structural strength of the part, a } 0.5 \mathrm{~mm} \text { layer thickness was } \\
\text { selected. The wall thickness of the part was selected as } 2 \mathrm{~mm} \text {, i.e., four times the layer thickness }\end{array}$ \\
\hline Geometrical features & The model did not have fillets, knife edges or small features \\
\hline Part orientation & $\begin{array}{l}\text { Part orientation was set with the minimum height matching the build orientation in order to reduce the production } \\
\text { time }\end{array}$ \\
\hline Path planning & A hollow structure was considered to reduce part cost, production time, material use, and part weight \\
\hline Stability and post-processing & $\begin{array}{l}\text { In order to ensure the stability of the part during its construction and to reduce the support structures, the largest and } \\
\text { flat surface of the model was selected as the basis. Post-processing work was considered to remove the support } \\
\text { structures, improve the surface finish and eliminate the staircase effect }\end{array}$ \\
\hline Design with materials & $\begin{array}{l}\text { ABS was selected as the part material because it will not be subjected to mechanical loads. PLA was selected as the } \\
\text { support material because it can be removed by dipping the part into water at a temperature above } 80^{\circ} \mathrm{C} \text { [ } 92 \text { ] }\end{array}$ \\
\hline Part cost & A hollow structure was considered to reduce part cost, production time, material use, and part weight \\
\hline
\end{tabular}

\section{Table 7 DfAM strategies for sustainability}

Table 8 Results of applying the proposed DfAM strategies to case study 1 


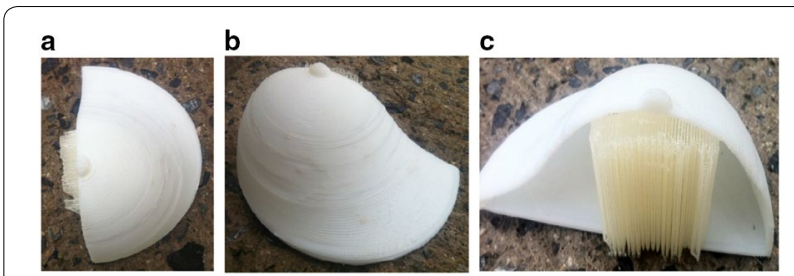

Figure 6 Breast implant prototype (sliced prototype): a) top view, b) front view, c) internal cavity, wall thickness and support structures

\subsubsection{Environmental Resistance}

The environmental resistance of a component can be defined in terms of environmental variables such as temperature, humidity, UV radiation, chemical exposure, and corrosion, among others. FDM fabricated parts are resistant to weather conditions only for a short period of time since most of the FDM materials are polymers with limited environmental exposure resistances. Therefore, if a higher environmental strength is required, additional treatments must be applied to the FDM parts. In addition, there are special FDM materials with high thermal, chemical and tensile resistance, such as the ULTEM from Stratasys $\odot$.

Thus, the proposed DfAM strategies for sustainability are shown in Table 7 . Since the product sustainability is also affected by its functionality, the previous FDM design and manufacturing strategies (Tables 3, 4 and 6) should be also considered to assure the product sustainability.

\section{Implementation}

To demonstrate the use of the proposed design and manufacturing strategies for FDM, three case studies were selected and correspond to the design of three components intended to be fabricated in a 3DTouch (from 3D systems ${ }^{\circledR}$ ) FDM system, with a build volume of $275 \mathrm{~mm} \times 275 \mathrm{~mm} \times 210 \mathrm{~mm}$ and three layer thickness values: $0.125 \mathrm{~mm}, 0.25 \mathrm{~mm}$ and $0.5 \mathrm{~mm}$.

\subsection{Case Study 1}

This case study corresponds to the design and fabrication of a breast implant pattern to produce a mould. The size of the breast implant is $170 \mathrm{~mm} \times 120 \mathrm{~mm} \times 80 \mathrm{~mm}$. From the analysis and application of the proposed DfAM strategies, the decisions and modifications shown in Table 8 were made. Figure 6 shows the breast implant after its fabrication.

\subsection{Case Study 2}

The second case study corresponds to an oil gear pump assembly. The end use of this component was to evaluate different assembly plans and sequences. The gear pump comprises five parts: one pump casing with dimensions $140 \mathrm{~mm} \times 105 \mathrm{~mm} \times 80 \mathrm{~mm}$, two bearings with dimensions $90 \mathrm{~mm} \times 50 \mathrm{~mm} \times 20 \mathrm{~mm}$, one drive gear shaft with dimensions $55 \mathrm{~mm} \times 55 \mathrm{~mm} \times 120 \mathrm{~mm}$ (shaft diameter $22 \mathrm{~mm}$ ), and one driven gear shaft with dimensions $55 \mathrm{~mm} \times 55 \mathrm{~mm} \times 80 \mathrm{~mm}$ (shaft diameter $22 \mathrm{~mm}$ ). The decisions shown in Table 9 were made from the analysis

\section{Table 9 Results of applying the proposed DfAM strategies to case study 2}

\begin{tabular}{|c|c|}
\hline Design for AM guidelines & Design and fabrication decisions \\
\hline Support structures, cavities and overhangs & $\begin{array}{l}\text { To reduce the use of support structures and avoid cavities, parts were orientated as shown in Figure } 7 . \text { The } \\
\text { pump casing was orientated with the holes axes matching the build direction }\end{array}$ \\
\hline Part size & $\begin{array}{l}\text { Since the dimensions of each part were smaller than the system workspace, part size problems were not } \\
\text { envisaged, each part was fabricated separately }\end{array}$ \\
\hline Thin sections & To reduce the production time a 0.5 mm layer thickness was selected \\
\hline Geometrical features & The small holes of the pump casing were orientated vertically \\
\hline Part orientation & $\begin{array}{l}\text { To reduce the use of support structures and to guarantee the stability of the parts during construction, } \\
\text { parts were orientated as shown in Figure } 7\end{array}$ \\
\hline $\begin{array}{l}\text { Path planning } \\
\text { Distortion, shrinkage \& warping } \\
\text { Accuracy }\end{array}$ & $\begin{array}{l}\text { To increase the accuracy of the component and avoid distortions or warping, a closed and alternating } \\
\text { filling pattern was used in all parts }\end{array}$ \\
\hline Stability and post-processing & $\begin{array}{l}\text { In order to ensure the stability of the parts during construction, the parts were orientated as shown in } \\
\text { Figure } 7 \text {. Post-processing was considered to remove the support structures of the gears, improve the } \\
\text { surface finish and eliminate the staircase effect }\end{array}$ \\
\hline Design with materials & $\begin{array}{l}\text { The ABS was selected as the part material because the parts won't be under mechanical loads. The PLA } \\
\text { was selected as the support material }\end{array}$ \\
\hline Part cost & The parts were orientated to reduce the use of support structures and material \\
\hline
\end{tabular}




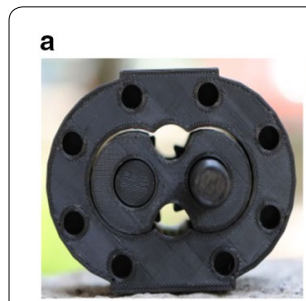

c
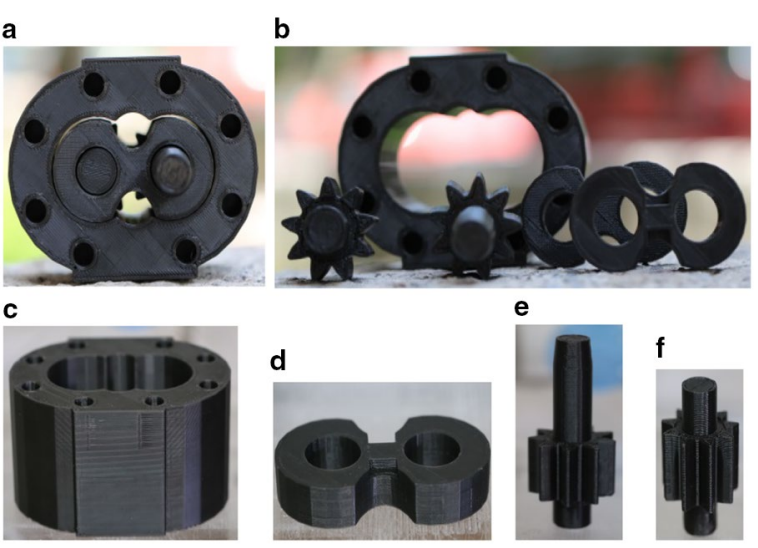

Figure 7 Gear pump: a) assembly, b) components of the gear pump, c) pump casing, d) gear bearing, e) drive gear shaft, f) driven gear shaft

and application of the proposed DfAM strategies. Figure 7 shows the gear pump components after their fabrication.

\subsection{Case Study 3}

The third case study corresponds to a pneumatic actuator assembly. The end purpose of this component was also to evaluate different assembly sequences. The pneumatic actuator comprises the following parts: two cap-end heads $(70 \mathrm{~mm} \times 75 \mathrm{~mm} \times 22 \mathrm{~mm})$, four screws $(\phi 8 \mathrm{~mm} \times 130 \mathrm{~mm})$, one piston and rod ( $\phi 50 \mathrm{~mm}, \phi 15 \mathrm{~mm} \times 160 \mathrm{~mm}$ ), and one cylinder $(\phi 55 \mathrm{~mm} \times 115 \mathrm{~mm})$. From the analysis and application of the proposed DfAM strategies to the pneumatic actuator, the decisions and modifications shown in Table 10

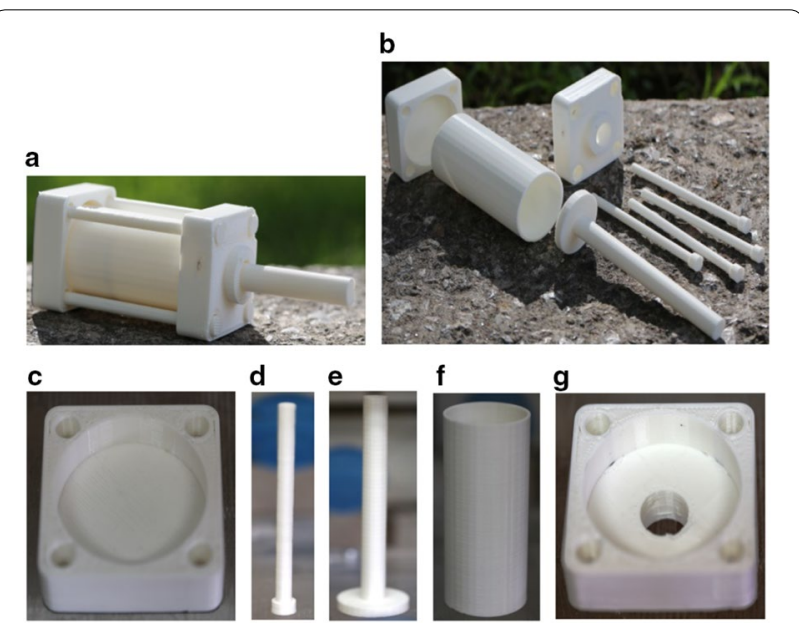

Figure 8 Pneumatic actuator: a) assembly, b) components, c) cap-end head, d) screw, e) piston, f) cylinder, g) rod-end head

were made. Figure 8 shows the pneumatic actuator components after their fabrication.

\section{Conclusions}

In this paper a complete review and analysis of design and manufacturing strategies for Fused Deposition Modelling has been presented. As a result, a comprehensive set of design for additive manufacturing strategies have been proposed based on the main technical limitations and drawbacks of current FDM technologies and systems. The proposed DfAM strategies have been divided into four main groups: geometry, quality, materials and sustainability. Since FDM technologies are continuously evolving, it is recommended to consider the capabilities

\section{Table 10 Results of applying the proposed DfAM strategies to case study 3}

\begin{tabular}{|c|c|}
\hline Design for AM guideline & Decisions \\
\hline Support structures, cavities and overhangs & $\begin{array}{l}\text { To reduce the use of support structures and avoid cavities and overhangs, parts were orientated as shown } \\
\text { in Figure } 8 \text {. According to these part orientations, none support structures were needed }\end{array}$ \\
\hline Part size & $\begin{array}{l}\text { Since the dimensions of each part were smaller than the system workspace, part size problems were not } \\
\text { envisaged and each part was fabricated separately }\end{array}$ \\
\hline Thin sections & $\begin{array}{l}\text { To reduce the production time and increase the structural strength of the part, a } 0.5 \mathrm{~mm} \text { layer thickness } \\
\text { was selected }\end{array}$ \\
\hline Geometrical features & Small holes of the cap-end heads were orientated vertically \\
\hline Part orientation & $\begin{array}{l}\text { To reduce the use of support structures, and to guarantee the stability of the parts during construction, } \\
\text { parts were orientated as shown in Figure } 8\end{array}$ \\
\hline $\begin{array}{l}\text { Path planning } \\
\text { Distortion, shrinkage \& warping } \\
\text { Accuracy }\end{array}$ & $\begin{array}{l}\text { To increase the accuracy of the components and avoid distortion or warping, a closed and alternating } \\
\text { filling pattern was used in all parts }\end{array}$ \\
\hline Stability and post-processing & $\begin{array}{l}\text { All parts were orientated with the largest flat area matching the build platform to ensure stability during } \\
\text { fabrication, Figure } 8 \text {. Post-processing work was considered to improve the surface finish and eliminate } \\
\text { the staircase effect }\end{array}$ \\
\hline Design with materials & $\begin{array}{l}\text { The ABS was selected as the part material because it will not be under mechanical loads. The PLA was } \\
\text { selected as the support material }\end{array}$ \\
\hline Part cost & To reduce the use of support structures and material, the parts were orientated as shown in Figure 8 \\
\hline
\end{tabular}


of the FDM system to be used. The DfAM strategies are intended to assist designers when making decisions at the design stage in order to satisfy functional needs, while ensuring manufacturability in FDM systems, and to assist manufacturers during the fabrication of parts in FDM systems. Moreover, the new prosed set of DfAM strategies can be extended to other types of AM processes besides the FDM process.

\begin{abstract}
Abbreviations
ABS: Acrylonitrile-Butadiene-Styrene; AM: Additive Manufacturing; ASTM: American Society for Testing Materials; BPM: Ballistic Particle Manufacture; CC: Contour Crafting; DfAM: Design for Additive Manufacturing; EFF: Extrusion Free Forming; FDC: Fused Deposition of Ceramics; FDM: Fused Deposition Modelling; PLA: Polylactic Acid; RP: Rapid Prototyping; RM: Rapid Manufacturing; SDM: Shaped Deposition Manufacture.
\end{abstract}

\section{Authors' Contributions}

HIMC was in charge of the research project and the whole trial, review of existing research works, analysis of the Design and for Additive Manufacturing strategies, and writing up of the manuscript. JZS carried out some literature review, compilation of strategies and execution of the case studies. Both authors read and approved the final manuscript.

\section{Authors' Information}

Hugo I. Medellín-Castillo is currently a full-time Professor at Universidad Autonoma de San Luis Potosi, Mexico. He received his PhD degree from HeriotWatt University, Scotland, UK, in 2006. His research interests include Additive Manufacturing, Virtual Design and Manufacturing, and Metal Forming. Jorge Zaragoza-Siqueiros is currently a PhD candidate at Universidad Autonoma de San Luis Potosi, Mexico. He received his master's degree in mechanical engineering from Universidad Autonoma de San Luis Potosi, Mexico, in 2014. His research interest is Additive Manufacturing and Virtual Engineering.

\section{Acknowledgements}

The second author would like to thank CONACYT for the scholarship provided during his postgraduate studies.

\section{Competing Interests}

The authors declare that they have no competing interests.

\section{Funding}

Supported by National Science and Technology Council (CONACYT) of Mexico (Grant No. CB-2010-01-154430), PROMEP Program of the Public Education Secretariat (SEP) of Mexico, and Fund for Research Support (FAI) of UASLP.

Received: 15 June 2018 Accepted: 29 May 2019

Published online: 13 June 2019

\section{References}

[1] H I Medellín-Castillo, J E Torres. Rapid prototyping and manufacturing: A review of current technologies. Proceedings of the ASME 2009 International Mechanical Engineering Congress and Exposition, USA, 2009: 609-621.

[2] ASTM F2792-09. Standard Terminology for Additive Manufacturing Technologies. ASTM International, West Conshohocken, PA, USA, 2009. http:// www.astm.org.

[3] G Pahl, W Beitz, J Feldhusen, et al. Engineering design, A systematic Approach. 3rd ed. London, UK: Springer, 2007.

[4] G E Dieter, L C Schmidt. Engineering design. New York, NY, USA: McGrawHill Higher Education, 2008.

[5] P Kulkarni, A Marsan, D Dutta. A review of process planning techniques in layered manufacturing. Rapid Prototyping Journal, 2000, 6: 18-35.
[6] Ali Khoshkhoo, Andres L. Carrano, David M. Blersch. Effect of build orientation and part thickness on dimensional distortion in material jetting processes. Rapid Prototyping Journal, 2018, 24(9): 1563-1571.

[7] R Hague, S Mansour, N Saleh. Design opportunities with rapid manufacturing. Assembly Automation, 2003, 23: 346-356.

[8] D M Anderson. Design for manufacturability \& concurrent engineering: how to design for low cost, design in high quality, design for lean manufacture, and design quickly for fast production. California, USA: CIM Press, 2004.

[9] Omar Ahmed Mohamed, Syed Hasan Masood, Jahar Lal Bhowmik. Mathematical modeling and FDM process parameters optimization using response surface methodology based on Q-optimal design. Applied Mathematical Modelling, 2016, 40(23-24): 10052-10073.

[10] H Medellin, T Lim, J Corney, et al. Automatic subdivision and refinement of large components for rapid prototyping production. Journal of Computing and Information Science in Engineering, 2007, 7: 249-258.

[11] D Dimitrov, K Schreve, A Taylor, et al. Rapid prototyping driven design and realisation of large components. Rapid Prototyping Journal, 2007, 13(2): 85-91.

[12] B Vayre, F Vignat, F Villeneuve. Designing for additive manufacturing. Procedia CIRP, 2012, 3: 632-637.

[13] Christoph Klahn, Bastian Leutenecker, Mirko Meboldt. Design strategies for the process of additive manufacturing. Procedia CIRP, 2015, 36: 230-235.

[14] Haeseong Jee, Paul Witherell. A method for modularity in design rules for additive manufacturing. Rapid Prototyping Journal, 2017, 23(6): $1107-1118$.

[15] Germain Sossou, Frédéric Demoly, Ghislain Montavon, et al. An additive manufacturing oriented design approach to mechanical assemblies. Journal of Computational Design and Engineering, 2018, 5(1): 3-18.

[16] I Gibson, D W Rosen, B Stucker. Additive manufacturing technologies: Rapid prototyping to direct digital manufacturing. New York, NY, USA: Springer, 2010.

[17] E L Doubrovski, J C Verlinden, I Horvath. First steps towards collaboratively edited design for additive manufacturing knowledge. Solid Freeform Fabrication Symposium, 2012: 891-901.

[18] R Ponche, J Y Hascoet, O Kerbrat, et al. A new global approach to design for additive manufacturing. Virtual and Physical Prototyping, 2012, 7(2): 93-105.

[19] M B Comellas. Design for additive manufacturing. Technical University of Denmark, Kgs. Lyngby, Denmark, 2013.

[20] DW Rosen. Research supporting principles for design for additive manufacturing. Virtual and Physical Prototyping, 2014, 9(4): 225-232.

[21] G A O Adam, D Zimmer. Design for additive manufacturing-Element transitions and aggregated structures. CIRP Journal of Manufacturing Science and Technology, 2014, 7: 20-28.

[22] A H Azman, FVignat, FVilleneuve. Evaluating current CAD tools performances in the context of design for additive manufacturing. Conference on Mechanical, Design Engineering \& Advanced Manufacturing, 2014.

[23] M Kumke, H Watschke, Vietor Thomas. A new methodological framework for design for additive manufacturing. Virtual and Physical Prototyping, 2016, 11(1): 3-19.

[24] Hällgren Sebastian, Pejrydb Lars, Ekengrenb Jens. (Re)Design for additive manufacturing. Procedia CIRP, 2016, 50: 246-251.

[25] A W Gebisa, H G Lemu. Design for manufacturing to design for Additive Manufacturing: Analysis of implications for design optimality and product sustainability. Procedia Manufacturing, 2017, 13: 724-731.

[26] Z Doubrovski, J C Verlinden, J P Geraedts. Optimal design for additive manufacturing: Opportunities and challenges. Proceedings of the ASME Design Engineering Technical Conference, Washington, DC, USA, 2011, 9: 635-646.

[27] SASAM. Additive manufacturing: SASAM standardisation roadmap. AM Platform, European Technology Platform in Additive Manufacturing, 2015

[28] A Scott, TP Harrison. Additive manufacturing in an end-to-end supply chain setting. 3D Printing and Additive Manufacturing, 2015, 2(2): 65-77.

[29] M K Thompson, G Moroni, TVaneker, et al. Design for additive manufacturing: Trends, opportunities, considerations, and constraints. CIRP Annals - Manufacturing Technology, 2016, 65: 737-760.

[30] Ruth Jiang, Robin Kleer, FrankT. Piller. Predicting the future of additive manufacturing: A Delphi study on economic and societal implications of 3D printing for 2030. Technological Forecasting and Social Change, 2017, 117: 84-97. 
[31] Syed A.M. Tofail, Elias P. Koumoulos, Amit Bandyopadhyay, et al. Additive manufacturing: scientific and technological challenges, market uptake and opportunities. Materials Today, 2018, 21(1): 22-37.

[32] ASTM F2792-12a. Standard Terminology for Additive Manufacturing Technologies. ASTM International, West Conshohocken, PA, USA, 2012, http:// www.astm.org.

[33] D Pham, R Gault. A comparison of rapid prototyping technologies. International Journal of Machine Tools and Manufacture, 1998, 38: 1257-1287.

[34] G N Levy, R Schindel, J P Kruth. Rapid manufacturing and rapid tooling with layer manufacturing $(\mathrm{LM})$ technologies, state of the art and future perspectives. CIRP Annals-Manufacturing Technology, 2003, 52: 589-609.

[35] I Gibson, D W Rosen, B Stucker. Additive manufacturing technologies: 3D printing, rapid prototyping, and direct digital manufacturing. New York, USA: Springer, 2014.

[36] Patrik Spalt, Thomas Bauernhansl. A framework for integration of additive manufacturing technologies in production networks. Procedia CIRP, 2016, 57: 716-721.

[37] H Ko, S K Moon, J Hwang. Design for additive manufacturing in customized products. Int. J. Precis. Eng. Manuf., 2015, 16(11): 2369-2375.

[38] Durgun Ismail, Ertan Rukiye. Experimental investigation of FDM process for improvement of mechanical properties and production cost. Rapid Prototyping Journal, 2014, 20(3): 228-235.

[39] F Rodríguez José, P Thomas James, E Renaud John. Mechanical behavior of acrylonitrile butadiene styrene (ABS) fused deposition materials: Experimental investigation. Rapid Prototyping Journal, 2001, 7(3): 148-158.

[40] Torres Jonathan, Cole Matthew, Owji Allen, et al. An approach for mechanical property optimization of fused deposition modeling with polylactic acid via design of experiments. Rapid Prototyping Journal, 2016, 22(2): 1-56.

[41] T Grimm. Stereolithography, Selective Laser Sintering and PolyJet ${ }^{\mathrm{TM}}$ : Evaluating and Applying the Right Technology. Accelerated Technologies, Inc., 2002.

[42] E Fodran, M Koch, U Menon. Mechanical and dimensional characteristics of fused deposition modeling build styles. Solid Freeform Fabrication Symposium, University of Texas, Austin, USA, 1996: 419-442.

[43] B Meyer. The accuracy myth, Don't Make the Mistake of Confusing High Resolution With Accuracy. Stratasys Inc, 2008.

[44] J Hur, K Lee. The development of a CAD environment to determine the preferred build-up direction for layered manufacturing. The International Journal of Advanced Manufacturing Technology, 1998, 14: 247-254.

[45] H S Byun, K H Lee. Determination of optimal build direction in rapid prototyping with variable slicing. The International Journal of Advanced Manufacturing Technology, 2006, 28: 307-313.

[46] Envision Tec Ltd. The benchmark in 3D printing, 2017 [Online], http://www. envisiontec.com/ (accessed June 2017).

[47] S Allen, D Dutta. On the computation of part orientation using support structures in layered manufacturing. Solid Freeform Fabrication Symposium, 1994: 259-269.

[48] J R Wodziak, G M Fadel, C Kirschman. A genetic algorithm for optimizing multiple part placement to reduce build time. Proceedings of the Fifth International Conference on Rapid Prototyping, 1994: 201-210.

[49] M Bablani, A Bagchi. Quantification of errors in rapid prototyping processes, and determination of preferred orientation of parts. TransactionsNorth American Manufacturing Research Institution of SME, 1995: 319-324.

[50] J Majhi, R Janardan, M Smid, et al. Multi-criteria geometric optimization problems in layered manufacturing. Proceedings of the Fourteenth Annual Symposium on Computational Geometry, ACM, 1998: 19-28.

[51] P Kulkarni, D Dutta. Deposition strategies and resulting part stiffnesses in fused deposition modeling. Journal of Manufacturing Science and Engineering, 1999, 121(1): 93-103.

[52] Leutenecker-Twelsieka Bastian, Klahnb Christoph, Meboldta Mirko. Considering part orientation in design for additive manufacturing. Procedia CIRP, 2016, 50: 408-413.

[53] G Moroni, W P Syam, S Petrò. Functionality-based part orientation for additive manufacturing. Procedia CIRP, 2015, 36: 217-222.

[54] G Moroni, W P Syam, S Petrò. Towards early estimation of part accuracy in additive manufacturing. Procedia CIRP, 2014, 21: 300-305.

[55] W Cheng, J Fuh, A Nee, et al. Multi-objective optimization of part-building orientation in stereolithography. Rapid Prototyping Journal, 1995, 1: $12-23$.
[56] F Xu, Y Wong, H Loh, et al. Optimal orientation with variable slicing in stereolithography. Rapid Prototyping Journal, 1997, 3: 76-88.

[57] F Xu, H Loh, Y Wong. Considerations and selection of optimal orientation for different rapid prototyping systems. Rapid Prototyping Journal, 1999, 5: 54-60.

[58] W R Chang. CAD/CAM for the selective laser sintering process. University of Texas, Austin, Texas, USA, 1989.

[59] S J Rock, M J Wozny. Utilizing topological information to increase scan vector generation efficiency. Solid Freeform Fabrication Symposium Proceedings, 1991: 28-36.

[60] J K Chari, J L Hall. Robust prototyping. Solid Freeform Fabrication Symposium, 1993: 135-142.

[61] H E Otto, F Kimura, F Mandorli, et al. Extension of feature-based CAD systems using TAE structures to support integrated rapid prototyping. Proceedings of the Computers in Engineering Conference and the Engineering Database Symposium, ASME, 1995: 779-793.

[62] Gray IV Robert W, Baird Donald G, Bøhn Jan Helge. Effects of processing conditions on short TLCP fiber reinforced FDM parts. Rapid Prototyping Journal, 1998, 4(1): 14-25.

[63] F Rodriguez José, P Thomas James, E Renaud John. Maximizing the strength of the fused-deposition ABS plastic parts. Solid Freeform Fabrication Proceedings, University of Notre Dame, 1999: 335-342.

[64] F Rodriguez José, P Thomas James, E Renaud John. Characterization of the mesostructure of fused-deposition acrylonitrile-butadiene-styrene materials. Rapid Prototyping Journal, 2000, 6(3): 175-186.

[65] Ker Chin Ang, Kah Fai Leong, Chee Kai Chua, et al. Investigation of the mechanical properties and porosity relationships in fused deposition modelling-fabricated porous structures. Rapid Prototyping Journal, 2006, 12(2): 100-105

[66] C S Lee, S G Kim, H J Kim, et al. Measurement of anisotropic compressive strength of rapid prototyping parts. Journal of Materials Processing Technology, 2007, 187-188: 627-630.

[67] Sood Anoop Kumar, R K Ohdar, S S Mahapatra. Parametric appraisal of mechanical property of fused deposition modelling processed parts. Materials and Design, 2010, 31(1): 287-295.

[68] Górski Filip, Kuczko Wiesław, Wichniarek Radosław. Computation of mechanical properties of parts manufactured by fused deposition modeling using finite element method. 10th International Conference on Soft Computing Models in Industrial and Environmental Applications, Advances in Intelligent Systems and Computing, 2015, 368: 403-413.

[69] E Pei, R I Campbell, D de Beer. Entry-level RP machines: how well can they cope with geometric complexity? Assembly Automation, 2011, 31: $153-160$.

[70] Xin Li, Zhuo Wang, Jianzhong Shang. Research on the warping deformation in fused deposition modeling. Asian Journal of Research in Chemistry and Pharmaceutical Sciences, 2016, 4(1): 21-30.

[71] Kotlinski Jaroslaw. Mechanical properties of commercial rapid prototyping materials. Rapid Prototyping Journal, 2014, 20(6): 499-510.

[72] A Bellini, S Guceri. Mechanical characterization of parts fabricated using fused deposition modeling. Rapid Prototyping Journal, 2003, 9(4): 252-264.

[73] U Ajoku, N Salesh, R J M Hague, et al. Investing mechanical anisotropy and end-of-vector effect in laser-sintered nylon parts. Journal of Engineering Manufacture, 2006, 220(7): 1077-1086.

[74] K Chockalingam, N Jawahar, U Chandrasekhar. Influence of layer thickness on mechanical properties in stereolithography. Rapid Prototyping Journal, 2006, 12(2): 106-113.

[75] G D Kim, YT Oh. A benchmark study on rapid prototyping processes and machines: quantitative comparisons of mechanical properties, accuracy, roughness, speed, and material cost. Proceedings of the Institution of Mechanical Engineers-Part B-Engineering Manufacture, 2008, 222(2): 201-215.

[76] Majewski Candice, Hopkinson Neil. Effect of section thickness and build orientation on tensile properties and material characteristics of laser sintered nylon-12 parts. Rapid Prototyping Journal, 2011, 17(3): 176-180.

[77] de Oliveira Grazielle Setti, Fernandes de Oliveira Marcelo, Alves Maia Izaque, et al. Correlation between mechanical and surface properties of SLS parts. Rapid Prototyping Journal, 2014, 20(4): 285-290.

[78] Farzad Rayegani, Godfrey C. Onwubolu. Fused deposition modeling (FDM) process parameter prediction and optimization using group 
method for data handling (GMDH) and differential evolution (DE). Int J Adv Manuf Technology, 2014, 73: 509-519.

[79] Lanzotti Antonio, Grasso Marzio, Staiano Gabriele, et al. The impact of process parameters on mechanical properties of parts fabricated in PLA with an open-source 3-D printer. Rapid Prototyping Journal, 2015, 2(5): 604-617.

[80] H Rezayat, W Zhou, A Siriruk, et al. Structure-mechanical property relationship in fused deposition modelling. Material Science and Technology, 2015, 31(8): 895-903.

[81] Omar Ahmed Mohamed, Syed Hasan Masood, Jahar Lal Bhowmik. Analysis of wear behavior of additively manufactured PC-ABS parts. Materials Letters, 2018, 230: 261-265.

[82] J Wang, L L Shaw. Fabrication of functionally graded materials via inkjet color printing. Journal of the American Ceramic Society, 2006, 89(10): 3285-3289.

[83] DW Rosen. Computer-aided design for additive manufacturing of cellular Structures. Computer-Aided Design \& Applications, 2007, 4(5): 585-594.

[84] C Chu, G Graf, D W Rosen. Design for additive manufacturing of cellular structures. Computer-Aided Design and Applications, 2008, 5(5): 686-696.

[85] Tanlak Niyazi, Dirk Frederik De Lange, Wim Van Paepegem. Numerical prediction of the printable density range of lattice structures for additive manufacturing. Materials \& Design, 2017, 133: 549-558.

[86] Jatender Pal Singh, Pulak Mohan Pandey. Fabrication and assessment of mechanical properties of open cell porous regular interconnected metallic structure through rapid manufacturing route. Rapid Prototyping Journal, 2018, 24(1): 138-149.
[87] Michał Kucewicz, Paweł Baranowski, Jerzy Małachowski, et al. Modelling, and characterization of 3D printed cellular structures. Materials \& Design 2018, 142: 177-189.

[88] Diegel Olaf, Singamneni Sarat, Reay Stephen, et al. Tools for sustainable product design: Additive manufacturing. Journal of Sustainable Development, 2010, 3: 68-75.

[89] Jeremy Faludi, Cindy Bayley, Suraj Bhogal, Myles Iribarne. Comparing environmental impacts of additive manufacturing vs traditional machining via life-cycle assessment. Rapid Prototyping Journal, 2015, 21(1): $14-33$.

[90] D Frățilă, H Rotaru. Additive manufacturing-a sustainable manufacturing route. The 4th Int. Conf. on Computing and Solutions in Manuf. Eng. (CoSME'16), Braşov, Romania, 2016.

[91] D Freitas, H A Almeida, H Bártolo, et al. Sustainability in extrusion-based additive manufacturing technologies. Progress in Additive Manufacturing, 2016, 1(1-2): 65-78

[92] K M Nampoothiri, N R Nair, R P John. An overview of the recent developments in polylactide (PLA) research. Bioresource Technology, 2010, 101: 8493-8501

\section{Submit your manuscript to a SpringerOpen ${ }^{\odot}$ journal and benefit from:}

- Convenient online submission

- Rigorous peer review

- Open access: articles freely available online

- High visibility within the field

- Retaining the copyright to your article

Submit your next manuscript at $\gg$ springeropen.com 